\title{
Changes in plasma endocannabinoid levels in viscerally obese men following a 1 year lifestyle modification programme and waist circumference reduction: associations with changes in metabolic risk factors
}

\author{
V. Di Marzo • M. Côté • I. Matias • I. Lemieux • \\ B. J. Arsenault • A. Cartier • F. Piscitelli • S. Petrosino • \\ N. Alméras • J.-P. Després
}

Published online: 30 October 2008

(C) Springer-Verlag 2008

\begin{abstract}
Aims/hypothesis We previously reported that the plasma levels of the endocannabinoid, 2-arachidonoylglycerol (2-AG), in a cohort of viscerally obese men are directly correlated with visceral adipose tissue (VAT) accumulation and metabolic risk factors including low HDL-cholesterol and high triacylglycerol. It is not known, however, if such
\end{abstract}

Electronic supplementary material The online version of this article (doi:10.1007/s00125-008-1178-6) contains supplementary material, which is available to authorised users.

V. Di Marzo $(\bowtie) \cdot$ I. Matias $\cdot$ F. Piscitelli $\cdot$ S. Petrosino Endocannabinoid Research Group, Istituto di Chimica Biomolecolare, Consiglio Nazionale delle Ricerche, Via Campi Flegrei 34, Comprensorio Olivetti, 80078 Pozzuoli (NA), Italy

e-mail:vdimarzo@icmib.na.cnr.it

M. Côté $\cdot$ I. Lemieux · B. J. Arsenault · A. Cartier · N. Alméras • J.-P. Després $(\varangle)$

Québec Heart Institute, Hôpital Laval Research Centre,

2725, chemin Ste-Foy, Pavilion Marguerite-D'Youville, 4th Floor, Québec, QC, Canada G1V 4G5

e-mail: jean-pierre.despres@crhl.ulaval.ca

M. Côté • B. J. Arsenault • A. Cartier

Department of Anatomy and Physiology, Laval University,

Québec, QC, Canada

I. Matias

U862 Centre de Recherche INSERM François Magendie,

Bordeaux, France

J.-P. Després

Division of Kinesiology, Department of Social and Preventive

Medicine, Laval University, Québec,

QC, Canada correlations persist after vigorous lifestyle interventions that reduce metabolic risk factors. We analysed the changes in endocannabinoid levels in a subsample from the same cohort following a 1 year lifestyle modification programme, and correlated them with changes in VAT and metabolic risk factors.

Methods Forty-nine viscerally obese men (average age 49 years, BMI $30.9 \mathrm{~kg} / \mathrm{m}^{2}$, waist $107.3 \mathrm{~cm}$ ) underwent a 1 year lifestyle modification programme including healthy eating and physical activity. Plasma levels of 2-AG and the other most studied endocannabinoid, anandamide, were measured by liquid chromatography-mass spectrometry. Anthropometric and metabolic risk factors, including VAT, insulin resistance and glucose intolerance, HDL-cholesterol and triacylglycerol, were measured.

Results Most risk factors were improved by the intervention, which led to a significant decrease in body weight $(-6.4 \mathrm{~kg}$, $p<0.0001)$, waist circumference $(-8.0 \mathrm{~cm}, p<0.0001)$ and VAT $(-30 \%, p<0.0001)$, and in plasma $2-\mathrm{AG}(-62.3 \%$, $p<0.0001)$ and anandamide $(-7.1 \%, p=0.005)$ levels. The decrease in levels of 2-AG but not those of anandamide correlated with decreases in VAT and triacylglycerol levels, and with the increase in $\mathrm{HDL}_{3}$-cholesterol levels. Multivariate analyses suggested that decreases in 2-AG and VAT were both independently associated with decreases in triacylglycerol.

Conclusions/interpretation This study shows that a strong correlation exists between 2-AG levels and high plasma triacylglycerol and low $\mathrm{HDL}_{3}$-cholesterol in viscerally obese men.

Keywords Dyslipidaemia · Endocannabinoids . HDL-cholesterol · Insulin resistance - Obesity . Type 2 diabetes 


$\begin{array}{ll}\text { Abbreviations } \\ \text { 2-AG } & \text { 2-arachidonoylglycerol } \\ \text { CRP } & \text { C-reactive protein } \\ \text { EC } & \text { endocannabinoid } \\ \text { InsRes } & \text { variable of insulin resistance } \\ \text { RepIns30 } & \text { variable of insulin resistance } \\ \text { SAT } & \text { subcutaneous adipose tissue } \\ \text { TG } & \text { triacylglycerol } \\ \text { VAT } & \text { visceral adipose tissue }\end{array}$

\section{Introduction}

Elevated concentrations of endogenous agonists of cannabinoid $\mathrm{CB}_{1}$ receptors (endocannabinoids [ECs]) in tissues are associated with obesity and with excess visceral adipose tissue (VAT) accumulation and related metabolic abnormalities (high plasma triacylglycerols [TGs], low HDL-cholesterol, high fasting glucose and insulin levels, insulin resistance; see [1] for a recent review). In obese patients, higher levels of the EC, 2-arachidonoylglycerol (2-AG), but not of another EC, anandamide, are found in VAT, but not subcutaneous adipose tissue (SAT), as compared with lean volunteers [2]. In two independent cross-sectional studies, increased plasma levels of 2-AG, but not anandamide, were shown to correlate with high levels of VAT, but not SAT, as well as with several of the aforementioned metabolic alterations [3, 4]. In view of the proposed pro-lipogenic and glucose intolerance-inducing actions of $\mathrm{CB}_{1}$ receptor stimulation in rodents [1], an upregulated EC system in the VAT of obese patients might lead to an increased VAT accumulation and contribute to ectopic fat accumulation and insulin resistance. However, whether interventions aimed at specifically reducing VAT in abdominally obese patients also reduce circulating EC levels has not been investigated. Therefore, it is not known if interventioninduced changes in EC levels correlate with changes in metabolic dysfunctions associated with VAT. Such an observation would establish a relationship between the overactive endocannabinoid system and some metabolic risk factors that is stronger than that implied by crosssectional studies $[3,4]$. In the present study, we aimed to obtain this information by investigating, in a sample of viscerally obese patients, the effect of a 1 year lifestyle modification programme, consisting of healthy eating and regular physical activity/exercise, on EC levels, VAT accumulation and metabolic cardiovascular risk factors.

\section{Methods}

The study included 49 asymptomatic men aged 32-65 years without diabetes, characterised by visceral obesity and high
TG-low HDL-cholesterol. Men were assigned to a personalised nutritional and physical activity exercise management programme offered by a multidisciplinary team which included a monthly visit to a dietitian and an exercise physiologist. All participants gave their written consent to participate in the study, which was approved by the Medical Ethics Committee of Hôpital Laval.

Anthropometric measurements were performed following standardised techniques [5]. Measurement of L4-L5 abdominal adipose tissue areas was performed by computed tomography [6]. Complete fasting plasma lipoprotein-lipid profile was obtained as described [4] and LDL particle size was measured by non-denaturing polyacrylamide gradient gel electrophoresis [7]. A $75 \mathrm{~g}$ OGTT was performed in the morning after an overnight fast. Plasma glucose and insulin were measured as described $[8,9]$. The total glucose and insulin AUCs during the OGTT were determined with the trapezoid method. Variables of insulin resistance were calculated using the equations: InsRes $=\{[$ fasting insulin $(\mathrm{pmol} / \mathrm{l}) / 7.2] \times$ fasting glucose $(\mathrm{mmol} / \mathrm{l})\} / 22.5$ and RepIns30 $=\{$ [fasting insulin $(\mathrm{pmol} / \mathrm{l})+$ insulin at $15 \mathrm{~min}$ $(\mathrm{pmol} / \mathrm{l})] / 2 \times 15\}+\{[$ insulin at $15 \mathrm{~min}(\mathrm{pmol} / \mathrm{l})+$ insulin at $30 \mathrm{~min}(\mathrm{pmol} / \mathrm{l})] / 2 \times 15\}-$ fasting insulin $(\mathrm{pmol} / \mathrm{l}) \times 30$ ], both derived from HOMA model at baseline.

EC levels were measured by isotope-dilution liquid chromatography-atmospheric pressure chemical ionisation-mass spectrometry as described [4]. Fasting plasma adiponectin, leptin (B-Bridge International, Mountain View, CA, USA) and IL-6 (R\&D Systems, Minneapolis, MN, USA) concentrations were determined by ELISA. Concentrations of high-sensitivity C-reactive protein (CRP) were measured with a highly sensitive immunoassay and performed with a Behring BN-100 nephelometer (Dade Behring, Marburg, Germany) as described [10]. Data as means \pm SD were analysed by the non-parametric Sign test for paired data. When variables were not normally distributed, a logarithmic transformation was used instead. Relationships between variables were assessed by Pearson's correlation, except for abnormally distributed variables which were assessed with Spearman's correlation and/or Pearson's correlation on log-transformed data. A $p$ value $<0.05$ indicated statistical significance.

\section{Results}

The 1 year intervention reduced body weight $(-6.4 \mathrm{~kg})$, BMI $\left(-2.1 \mathrm{~kg} / \mathrm{m}^{2}\right)$, waist circumference $(-8.0 \mathrm{~cm})$, VAT $\left(-79.3 \mathrm{~cm}^{2}\right)$ (Table 1) and supine diastolic and systolic BP $(-5.9 \pm 6.0$ and $-5.6 \pm 9.6 \mathrm{mmHg}$ from baselines of $82.3 \pm 6.6$ and $122.8 \pm 10.6 \mathrm{mmHg}, p \leq 0.0002$ ). It also significantly ameliorated nearly all conventional metabolic risk factors, including TGs $(-0.74 \mathrm{mmol} / \mathrm{l})$, HDL-cholesterol $(+0.13 \mathrm{mmol} / \mathrm{l})$, 
Table 1 Anthropometric and biochemical variables at baseline and following a 1 year lifestyle modification programme

\begin{tabular}{|c|c|c|c|c|c|c|}
\hline Variable & $n$ & Baseline & Post 1 year intervention & Absolute change & Change $(\%)$ & $p$ value \\
\hline Body weight $(\mathrm{kg})$ & 49 & $93.9 \pm 12.5$ & $87.5 \pm 13.4$ & $-6.4 \pm 4.5$ & $-6.9 \pm 4.9$ & $<0.0001$ \\
\hline BMI $\left(\mathrm{kg} / \mathrm{m}^{2}\right)$ & 49 & $30.9 \pm 3.3$ & $28.8 \pm 3.6$ & $-2.1 \pm 1.5$ & $-6.8 \pm 4.8$ & $<0.0001$ \\
\hline Waist circumference $(\mathrm{cm})$ & 49 & $107.3 \pm 9.8$ & $99.3 \pm 11.6$ & $-8.0 \pm 4.9$ & $-7.6 \pm 4.6$ & $<0.0001$ \\
\hline L4-L5 visceral AT $\left(\mathrm{cm}^{2}\right)$ & 49 & $270.9 \pm 82.4$ & $192.7 \pm 93.9$ & $-79.3 \pm 56.2$ & $-30.3 \pm 18.6$ & $<0.0001$ \\
\hline L4-L5 subcutaneous AT $\left(\mathrm{cm}^{2}\right)$ & 49 & $295.8 \pm 93.3$ & $242.0 \pm 97.6$ & $-52.5 \pm 43.3$ & $-18.5 \pm 13.0$ & $<0.0001$ \\
\hline Total cholesterol $(\mathrm{mmol} / \mathrm{l})$ & 47 & $5.12 \pm 0.70$ & $4.99 \pm 0.75$ & $-0.12 \pm 0.57$ & $-1.94 \pm 11.3$ & NS \\
\hline LDL-cholesterol (mmol/1) & 47 & $3.01 \pm 0.55$ & $3.11 \pm 0.70$ & $0.11 \pm 0.53$ & $3.98 \pm 18.1$ & NS \\
\hline VLDL-cholesterol (mmol/l) & 47 & $1.16 \pm 0.55$ & $0.80 \pm 0.41$ & $-0.36 \pm 0.43$ & $-27.8 \pm 29.3$ & $<0.0001$ \\
\hline HDL-cholesterol (mmol/l) & 47 & $0.95 \pm 0.16$ & $1.08 \pm 0.20$ & $0.13 \pm 0.14$ & $15.0 \pm 15.4$ & $<0.0001$ \\
\hline $\mathrm{HDL}_{2}$-cholesterol (mmol/l) & 47 & $0.33 \pm 0.10$ & $0.39 \pm 0.14$ & $0.07 \pm 0.11$ & $25.9 \pm 36.5$ & 0.0019 \\
\hline $\mathrm{HDL}_{3}$-cholesterol (mmol/l) & 47 & $0.62 \pm 0.10$ & $0.69 \pm 0.09$ & $0.06 \pm 0.08$ & $11.8 \pm 14.5$ & 0.0011 \\
\hline Non-esterified triacylglycerol $(\mathrm{mmol} / \mathrm{l})$ & 47 & $2.72 \pm 1.08$ & $2.00 \pm 0.77$ & $-0.74 \pm 1.05$ & $-22.2 \pm 29.4$ & $<0.0001$ \\
\hline LDL-triacylglycerol (mmol/l) & 47 & $0.31 \pm 0.14$ & $0.23 \pm 0.09$ & $-0.08 \pm 0.07$ & $-23.5 \pm 17.7$ & $<0.0001$ \\
\hline VLDL-triacylglycerol (mmol/1) & 47 & $2.15 \pm 0.94$ & $1.56 \pm 0.71$ & $-0.61 \pm 0.96$ & $-21.5 \pm 36.3$ & 0.0002 \\
\hline HDL-triacylglycerol (mmol/l) & 47 & $0.26 \pm 0.07$ & $0.21 \pm 0.05$ & $-0.05 \pm 0.06$ & $-17.6 \pm 18.0$ & $<0.0001$ \\
\hline Apolipoprotein B (g/l) & 47 & $1.08 \pm 0.16$ & $1.01 \pm 0.19$ & $-0.07 \pm 0.12$ & $-6.88 \pm 11.6$ & 0.003 \\
\hline Apolipoprotein A-I (g/l) & 47 & $1.11 \pm 0.15$ & $1.27 \pm 0.15$ & $0.15 \pm 0.11$ & $14.6 \pm 10.9$ & $<0.0001$ \\
\hline LDL particle size $(\AA)$ & 49 & $251.4 \pm 4.1$ & $252.9 \pm 3.9$ & $1.6 \pm 3.8$ & $0.65 \pm 1.49$ & 0.066 \\
\hline Fasting glucose $(\mathrm{mmol} / \mathrm{l})$ & 49 & $6.0 \pm 0.5$ & $6.0 \pm 0.5$ & $0.01 \pm 0.4$ & $0.39 \pm 6.03$ & NS \\
\hline Fasting insulin (pmol/1) & 49 & $169.8 \pm 82.8$ & $117.9 \pm 48.2$ & $-51.9 \pm 71.4$ & $-17.1 \pm 44.9$ & $<0.0001$ \\
\hline AUC glucose $(\mathrm{mmol} / 1 \times \mathrm{min})$ & 49 & $1,381 \pm 316$ & $1,291 \pm 355$ & $-90.2 \pm 318.2$ & $1.63 \pm 70.9$ & 0.09 \\
\hline AUC insulin $\left(\mathrm{pmol} / 1 \times \min \times 10^{-4}\right)$ & 49 & $16.5 \pm 7.8$ & $10.9 \pm 6.1$ & $-5.6 \pm 6.6$ & $-18.6 \pm 103.4$ & $<0.0001$ \\
\hline InsRes & 49 & $6.3 \pm 3.1$ & $4.4 \pm 1.9$ & $-1.9 \pm 2.8$ & $-15.9 \pm 47.5$ & 0.005 \\
\hline RepIns30 $\left(\times 10^{-3}\right)$ & 49 & $10.8 \pm 7.5$ & $7.9 \pm 6.1$ & $-2.9 \pm 7.3$ & $-28.6 \pm 100.3$ & 0.01 \\
\hline Leptin $(\mathrm{ng} / \mathrm{ml})$ & 49 & $12.1 \pm 9.4$ & $9.3 \pm 10.1$ & $-2.8 \pm 3.9$ & $-23.8 \pm 32.9$ & $<0.0001$ \\
\hline $\mathrm{CRP}(\mathrm{mg} / \mathrm{l})$ & 48 & $1.8 \pm 1.2$ & $1.3 \pm 1.9$ & $-0.6 \pm 1.5$ & $-31.6 \pm 47.0$ & $<0.0001$ \\
\hline IL-6 (pg/ml) & 49 & $1.3 \pm 1.0$ & $1.2 \pm 0.8$ & $-0.1 \pm 0.8$ & $3.58 \pm 58.4$ & NS \\
\hline Adiponectin $(\mu \mathrm{g} / \mathrm{ml})$ & 46 & $3.4 \pm 1.4$ & $4.1 \pm 1.3$ & $0.6 \pm 1.0$ & $27.7 \pm 47.0$ & 0.02 \\
\hline
\end{tabular}

Data are presented as means $\pm \mathrm{SD}$

VLDL-cholesterol $(-0.36 \mathrm{mmol} / \mathrm{l})$, fasting insulin levels $(-51.9 \mathrm{pmol} / \mathrm{l})$, AUCs for insulin and glucose levels $\left(-5.6 \mathrm{mmol} / / \times \min \times 10^{-4}\right.$ and $\left.-90.2 \mathrm{mmol} / / \times \min \right)$, as well as LDL particle size, high sensitivity-CRP and adiponectin levels, with no significant changes in LDL-cholesterol and fasting glucose levels (Table 1).

However, the 1 year intervention also caused a significant decrease in the plasma levels of anandamide $(-7.1 \%)$ and, particularly, 2-AG (-62.3\%; Fig. 1a,c).

Decreases in plasma 2-AG levels correlated positively with decreases in VAT $(r=0.30, p=0.04)$, total $(r=0.54$, $p<0.0001)$ and HDL- and VLDL-associated TGs $(r=0.48$, $p<0.0007$ and $r=0.50, p=0.0003$, respectively), and RepIns30, a measure of insulin resistance $(r=0.44$, $p=0.002)$, and with increases in $\mathrm{HDL}_{3}$-cholesterol $(r=-0.35$, $p<0.0001)$. Decreases in anandamide levels correlated inversely with decreases in fasting C-peptide levels $(r=-0.29$, $p=0.05)$, glucose and C-peptide AUCs $(r=-0.30, p=0.04$ and $r=-0.33, p=0.02$, respectively) and directly with decreases in IL-6 levels $(r=0.56, p<0.0001)$ (Electronic supplementary material Table 1). A stratification of partic- ipants according to tertiles of decreases in plasma 2-AG levels confirmed that these were associated with decreases in VAT and TG levels (Fig. 1b,d). Decreases in VAT correlated not only with decreases in TG $(r=0.62, p<0.0001)$ and increases in HDL-cholesterol $(r=-0.39, p=0.008)$, but also with decreases in leptin $(r=0.56, p<0.0001)$ and increases in adiponectin $(r=-0.59, p<0.0001)$.

Multivariate analyses using log-transformed changes in TG as dependent variable, and log-transformed changes in VAT and 2-AG as independent variables, showed that $13.7 \%(p<0.001)$ and $38.0 \%(p=0.0001)$ of the variation observed for TGs was explained by changes in 2-AG and VAT, respectively. When changes in log-fasting insulin and log-insulin AUC were the dependent variables, VAT was the only independent determinant to changes in insulin sensitivity variables, explaining $18.7 \%$ of the changes in fasting insulin $(p=0.002)$ and $12.3 \%$ of changes in AUC insulin $(p=0.02)$. When using changes in log-RepIns30 as dependent variable and changes in log-2-AG as independent variable, $20.3 \%(p=0.002)$ of the changes of the former were explained by the latter. However, changes in 




C
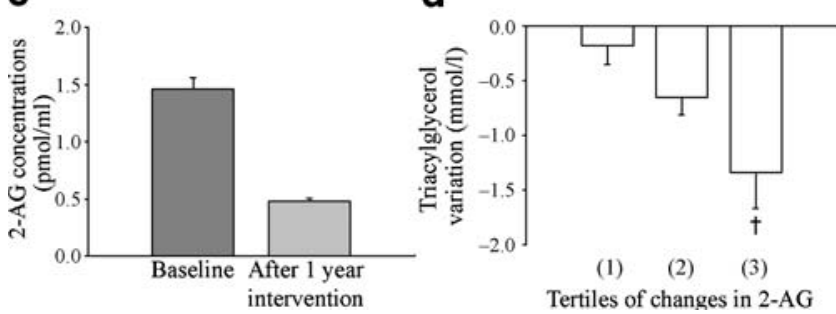

Fig. 1 Changes in anandamide (a) and 2-AG (c) plasma levels following 1 year lifestyle modification programme, and their baseline levels at the beginning of the study. Anandamide, change $-0.54 \mathrm{pmol} / \mathrm{l}$, $p<0.005 ; 2-\mathrm{AG}$, change $-0.98 \mathrm{pmol} / 1, p<0.005$. Variation in VAT (b) and TG (d) among tertiles of changes in 2-AG plasma levels (on the $x$ axis) following 1 year lifestyle modification programme [tertile (1): 2-AG changed from -0.08 to $-0.62 \mathrm{pmol} / \mathrm{ml}$; tertile (2): $2-\mathrm{AG}$ changed from -0.62 to $-1.20 \mathrm{pmol} / \mathrm{ml}$; tertile (3): $2-\mathrm{AG}$ changed from -1.20 to $-3.67 \mathrm{pmol} / \mathrm{ml}$. Data are presented as means with SE. Value significantly different from tertile $(1)$ : ${ }^{*} p<0.05$; value significantly different from tertiles (1) and (2): $\uparrow p<0.05$

2-AG did not contribute independently to changes of other insulin sensitivity indices (fasting insulin, AUC insulin, InsRes).

We then examined whether changes in other variables correlated with changes in metabolic cardiovascular risk factors. Changes in TG correlated with changes in fasting insulin ( $r=0.43, p<0.002)$, AUC insulin $(r=0.35, p<0.01)$, AUC glucose $(r=0.47, p=0.0008)$, InsRes $(r=0.43$, $p<0.0031)$ and leptin $(r=0.60, p<0.0001)$, but not CRP, IL-6 and adiponectin. Changes in HDL-cholesterol correlated with changes in adiponectin $(r=0.39, p=0.01)$, and in glucose and insulin AUCs ( $r=-0.41, p=0.004$ and $r=-0.48, p=0.0007)$. Changes in InsRes, fasting insulin and insulin AUC also correlated with changes in leptin $(r=0.34, p=0.02 ; r=0.33$, $p=0.02$; and $r=0.37, p=0.008$, respectively) and, for InsRes and fasting insulin only, also with changes in adiponectin ( $r=-0.38, p=0.01$ and $r=-0.37, p=0.01$, respectively). However, a multivariate analysis including log-transformed changes in VAT, SAT, 2-AG, leptin, adiponectin, CRP and IL-6 as independent variables and log-transformed changes in TG as dependent variable showed that changes in VAT, 2-AG and leptin formed the best predicting model, explaining $38.0 \%(p<0.0001), 13.7 \%(p=0.001)$ and $6.0 \%$ $(p=0.02)$ of the changes in TG levels independently of other metabolic variables.

\section{Discussion}

The present data indicate that a 1 year lifestyle modification programme leading to abdominal fat loss decreases, at the same time, several metabolic cardiovascular risk factors and plasma ECs. However, only the reduction in 2-AG correlated with intervention-induced beneficial changes in VAT, TG and $\mathrm{HDL}_{3}$-cholesterol, thus resembling in this way other metabolic factors such as leptin. Although with the unavoidable limitations of all correlative studies, the present results suggest a relationship between peripheral EC and $\mathrm{CB}_{1}$ receptor activity (in as much as these can be measured by plasma 2-AG levels) and VAT and dyslipidaemia (high TG and low HDL-cholesterol levels), a relationship which is possibly stronger than that suggested by previous cross-sectional studies [3, 4]. This finding is in agreement with the causative role, established in animal studies, of dysregulated EC levels in dyslipidaemia via direct actions on the adipose tissue and the liver [1]. In contrast, decreases in the levels of anandamide correlated with decreases in glucose tolerance and IL-6, reflecting, as in previous studies [2-4], different roles of plasma anandamide and 2-AG.

In view of the well-established role of VAT as a predictor of dyslipidaemia $[1,3,4,7]$, the above observations do not allow us to establish whether plasma 2-AG levels and VAT accumulation are independently associated with this risk factor. However, multivariate analyses allowed us to propose that elevated VAT accumulation and high peripheral 2-AG levels, although related to each other, act as two independent correlates of high TG levels. Clearly, 2-AG is only one of possibly several metabolic variables that correlate with this metabolic risk factor, since we have shown here that changes in plasma leptin levels also act as an independent predictor of changes in TG levels.

In conclusion, we have described here the first intervention study designed to assess whether changes in plasma EC levels correlate with changes in anthropometric and biochemical metabolic risk factors in viscerally obese men. Our data, together with previous findings in animals [1], might suggest that a peripherally overactive EC system in visceral obesity contributes to dyslipidaemia. However, since our data are still of a correlative nature, mechanistic studies will have to be performed to establish a cause-effect relationship between dysregulated EC levels and metabolic cardiovascular risk factors in humans.

Acknowledgements This work was funded by a grant from the Canadian Institutes of Health Research (awarded to J.-P. Després) as well as partly supported by a research grant from Sanofi-Aventis (to V. Di Marzo). 
Duality of interest The authors declare that there is no duality of interest associated with this manuscript.

\section{References}

1. Di Marzo V (2008) The endocannabinoid system in obesity and type 2 diabetes. Diabetologia 51:1356-1367

2. Matias I, Gonthier MP, Orlando P et al (2006) Regulation, function, and dysregulation of endocannabinoids in models of adipose and beta-pancreatic cells and in obesity and hyperglycemia. J Clin Endocrinol Metab 91:3171-3180

3. Bluher M, Engeli S, Kloting N et al (2006) Dysregulation of the peripheral and adipose tissue endocannabinoid system in human abdominal obesity. Diabetes 55:3053-3060

4. Côté M, Matias I, Lemieux I et al (2007) Circulating endocannabinoid levels, abdominal adiposity and related cardiometabolic risk factors in obese men. Int J Obes (Lond) 31:692-699

5. Lohman T, Roche A, Martorell R (1988) The Airlie (VA) consensus conference. In: Lohman TG, Roche A, Martorell R (eds) Anthropometric standardisation reference manual. Human Kinetics, Champaign, IL, pp 39-80

6. Ferland M, Després JP, Tremblay A et al (1989) Assessment of adipose tissue distribution by computed axial tomography in obese women: association with body density and anthropometric measurements. Br J Nutr 61:139-148

7. Tchernof A, Lamarche B, Prud'Homme D et al (1996) The dense LDL phenotype. Association with plasma lipoprotein levels, visceral obesity, and hyperinsulinemia in men. Diabetes Care 19:629-637

8. Richterich R, Dauwalder H (1971) Determination of plasma glucose by hexokinase-glucose-6-phosphate dehydrogenase method. Schweiz Med Wochenschr 101:615-618 (article in German)

9. Desbuquois B, Aurbach GD (1971) Use of polyethylene glycol to separate free and antibody-bound peptide hormones in radioimmunoassays. J Clin Endocrinol Metab 37:732-738

10. Ledue TB, Weiner DL, Sipe JD, Poulin SE, Collins MF, Rifai N (1998) Analytical evaluation of particle-enhanced immunonephelometric assays for C-reactive protein, serum amyloid A and mannose-binding protein in human serum. Ann Clin Biochem $35: 745-753$ 